\title{
Electronic physician notifications to improve guideline-based anticoagulation in atrial fibrillation: a randomized controlled trial
}

\author{
Jeffrey M. Ashburner, PhD, MPH ${ }^{1,2}$, Steven J. Atlas, MD, MPH ${ }^{1,2}$, Shaan Khurshid, MD ${ }^{2,3}$, \\ Lu-Chen Weng, $P h D^{4}$, Olivia L. Hulme, MD ${ }^{4}$, Yuchiao Chang, PhD ${ }^{1,2}$, Daniel E. Singer, MD ${ }^{1,2}$, \\ Patrick T. Ellinor, $M D, P h D^{4}$, and Steven A. Lubitz, MD, MPH ${ }^{4}$
}

'Division of General Internal Medicine, Massachusetts General Hospital, Boston, MA, USA; ${ }^{2}$ Department of Medicine, Harvard Medical School, Boston, MA, USA; ${ }^{3}$ Division of Cardiology, Massachusetts General Hospital, Boston, MA, USA; ${ }^{4}$ Cardiovascular Research Center and Cardiac Arrhythmia Service, Massachusetts General Hospital, Boston, MA, USA.

BACKGROUND: Oral anticoagulants reduce the risk of stroke in patients with atrial fibrillation. However, many patients with atrial fibrillation at elevated stroke risk are not treated with oral anticoagulants.

OBJECTIVE: To test whether electronic notifications sent to primary care physicians increase the proportion of ambulatory patients prescribed oral anticoagulants.

DESIGN: Randomized controlled trial conducted from February to May 2017 within 18 practices in an academic primary care network.

PARTICIPANTS: Primary care physicians $(n=175)$ and their patients with atrial fibrillation, at elevated stroke risk, and not prescribed oral anticoagulants.

INTERVENTION: Patients of each physician were randomized to the notification or usual care arm. Physicians received baseline email notifications and up to three reminders with patient information, educational material and primary care guidelines for anticoagulation management, and surveys in the notification arm.

MAIN MEASURES: The primary outcome was the proportion of patients prescribed oral anticoagulants at 3 months in the notification $(n=972)$ vs. usual care $(n=$ 1364) arms, compared using logistic regression with clustering by physician. Secondary measures included survey-based physician assessment of reasons why patients were not prescribed oral anticoagulants and how primary care physicians might be influenced by the notification.

KEY RESULTS: Over 3 months, a small proportion of patients were newly prescribed oral anticoagulants with no significant difference in the notification $(3.9 \%, 95 \% \mathrm{CI}$ 2.8-5.3\%) and usual care (3.2\%, 95\% CI 2.4-4.2\%) arms $(p=0.37)$. The most common, non-exclusive reasons why patients were not on oral anticoagulants included atrial fibrillation was transient (30\%) or paroxysmal (12\%), patient/family declined (22\%), high bleeding risk (20\%), fall risk (19\%), and frailty (10\%). For $95 \%$ of patients,

Electronic supplementary material The online version of this article (https://doi.org/10.1007/s11606-018-4612-6) contains supplementary material, which is available to authorized users.

Received February 13, 2018

Revised June 20, 2018

Accepted July 18, 2018

Published online August 3, 2018 physicians stated they would not change their management after reviewing the alert.

CONCLUSIONS: Electronic physician notification did not increase anticoagulation in patients with atrial fibrillation at elevated stroke risk. Primary care physicians did not prescribe anticoagulants because they perceived the bleeding risk was too high or stroke risk was too low.

TRIAL REGISTRATION: ClinicalTrials.gov identifier NCT02950285

KEY WORDS: atrial fibrillation; oral anticoagulation; primary care; electronic notifications; randomized controlled trial.

J Gen Intern Med 33(12):2070-7

DOI: $10.1007 / \mathrm{s} 11606-018-4612-6$

(C) Society of General Internal Medicine 2018

trial fibrillation (AF) is a prevalent arrhythmia and is $\mathrm{A}$ associated with a fivefold increased risk of ischemic stroke. ${ }^{1,2}$ Oral anticoagulation reduces the risk of stroke by approximately two-thirds. ${ }^{3}$ Despite the clear benefits of oral anticoagulation, studies have repeatedly demonstrated that about $40-50 \%$ of patients with $\mathrm{AF}$ and elevated stroke risk do not receive oral anticoagulants. ${ }^{4-11}$ A gap between physician awareness of patient eligibility for anticoagulation and guideline recommendations for stroke prevention has been cited as a potential factor for the apparent underuse of oral anticoagulation in patients with atrial fibrillation. ${ }^{10,12-14}$

It remains unclear whether addressing provider awareness of patient stroke risk can increase utilization of oral anticoagulants. Furthermore, there is limited understanding of current provider-based reasons for not prescribing oral anticoagulants in a contemporary adult cohort of patients with AF. Structured interventions using electronic medical record (EMR) decision support and electronic alert tools in patients with AF are feasible. ${ }^{15-17}$

We conducted a randomized controlled trial to test whether an electronic notification distributed to primary care physicians (PCPs) would increase the proportion of patients prescribed oral anticoagulants. Within the notification, we 
embedded educational support materials and a survey to assess who was making decisions regarding anticoagulation for each patient, the reasons why patients were not prescribed oral anticoagulants, and how PCPs might be influenced by the notification.

\section{METHODS}

\section{Setting and Participants}

This study was conducted in 18 primary care practices within Massachusetts General Hospital (MGH), with 180 PCPs (hereafter referred to as physicians) who cared for at least one patient with AF. Physicians were introduced to the study via email and given the choice of opting out. Of 180 physicians invited, five were omitted (two physicians opted-out, two were on extended leave, and one was not contacted due to incorrect contact information).

Among participating physicians, we identified 2336 patients in their care as of the study start date (February 7, 2017) ${ }^{18,19}$ who had a diagnosis of AF, elevated stroke risk and were not currently prescribed oral anticoagulants. We identified patients with AF by implementing a validated algorithm, using a population health management informatics system (TopCare, SRG Technology), ${ }^{20}$ based on billing codes, procedure codes, electrocardiograms, and medication prescriptions. ${ }^{21}$ We defined elevated stroke risk as a $\mathrm{CHA}_{2} \mathrm{DS}_{2}$-VASc score $\geq 2,{ }^{22}$ which was calculated by summing one point each for age $65-75$ years, the presence of congestive heart failure, hypertension, diabetes, vascular disease, and female sex, and two points for age $\geq$
75 years, or a prior stroke, transient ischemic attack, or systemic embolism. Covariates and use of oral anticoagulation were ascertained from the EMR as previously described. ${ }^{23}$ We have observed similar rates of oral anticoagulation use in this sample as compared to prior studies. ${ }^{23}$

\section{Study Design and Randomization}

We conducted a randomized, controlled trial to alert physicians of their patients with electronically ascertained AF and elevated stroke risk that were not currently prescribed oral anticoagulants (Fig. 1). Patients of each physician were randomized using a computerized random number generator to the intervention of physician notification at baseline or to the usual care control group without physician notification (all physicians were also offered the option to receive notifications for control patients after the trial period). To minimize physician burden, we limited the number of notifications to 10 per physician. For example, for physicians with 20 or fewer eligible patients, randomization was $1: 1$ to the intervention or usual care arms. For physicians with $\geq 21$ eligible patients, the intervention was randomly allocated for 10 patients and usual care for the remainder (Fig. 2).

We sent physician email alerts without regard to clinic visits for patients since we assumed that physicians would prescribe anticoagulation or modify treatment if the alert information was considered actionable and since physicians are often burdened with multiple alerts during clinic visits. ${ }^{24} \mathrm{We}$ assumed the likelihood of contamination in the usual care arm from the alerts was low since physicians were unaware of the patients in their panels randomized to usual care, alerts were distributed irrespective of a scheduled visit, and the trial period

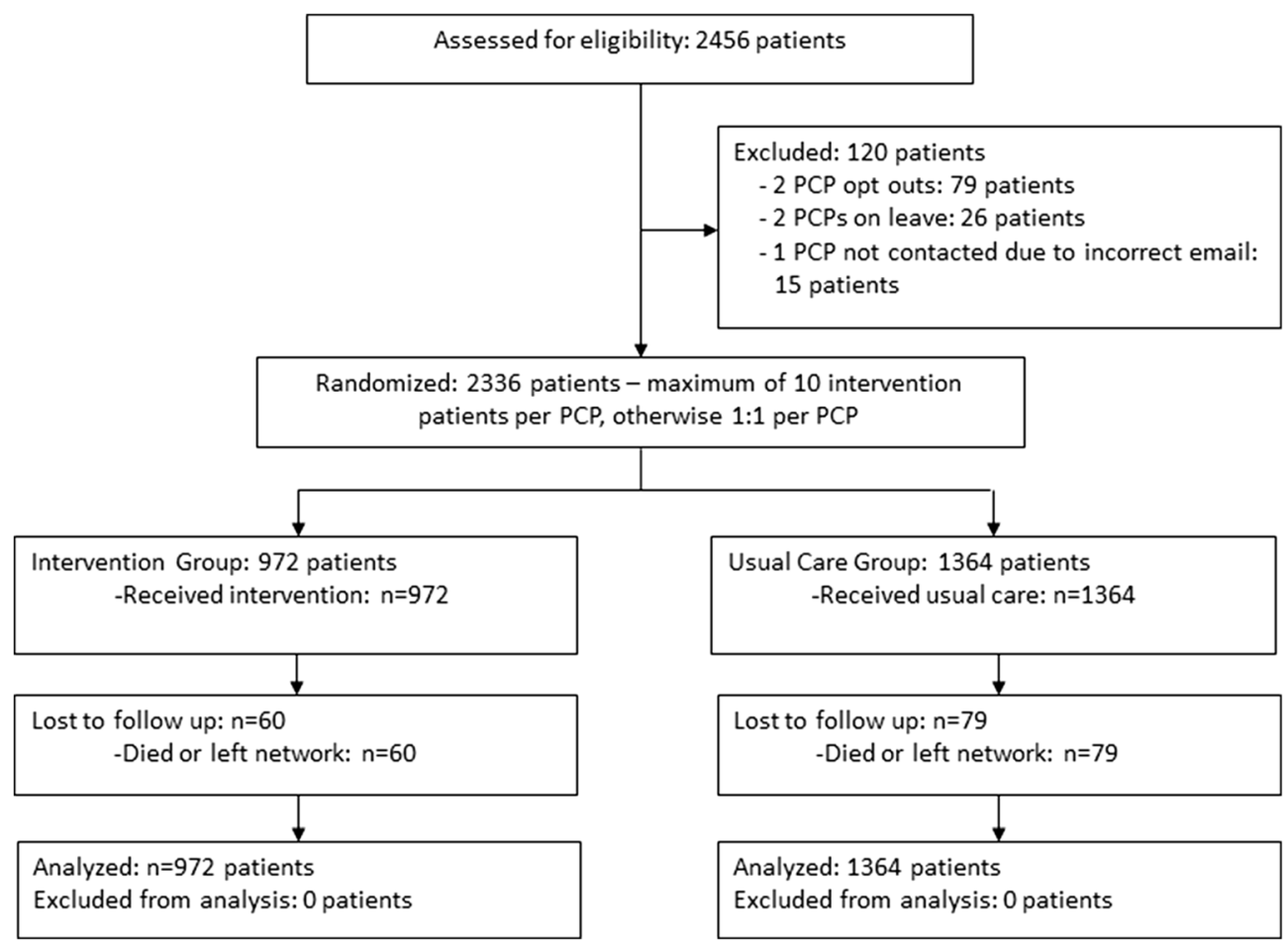

Figure 1 CONSORT diagram depicting flow of patients through randomization, intervention, and outcome analysis. 


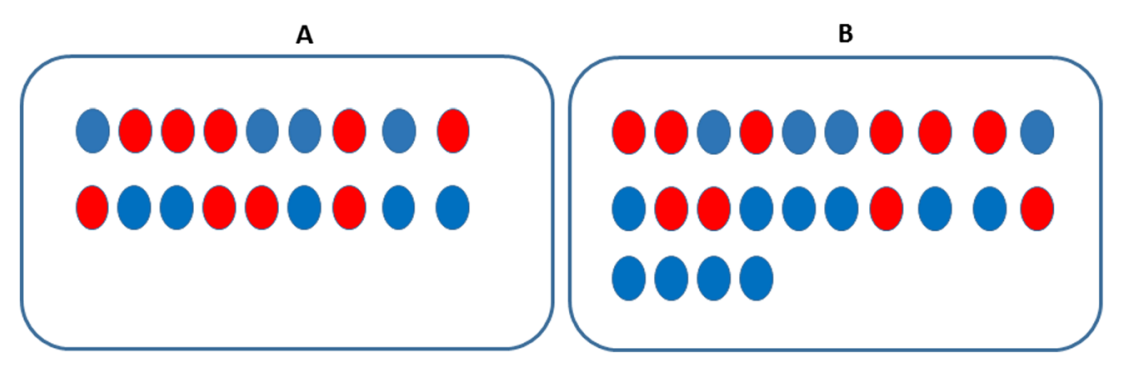

Figure 2 Schematic overview of patient-level randomization within physician panels. Panel A represents a hypothetical scenario in which a physician has $\leq \mathbf{2 0}$ eligible patients (circles). Each patient is randomized 1:1 to intervention (red) or usual care (blue). Panel B represents a hypothetical scenario in which a physician has $\geq 21$ eligible patients. 10 patients are randomly allocated to intervention (red), with the remainder to usual care (blue).

was brief in duration. We therefore performed randomization at the patient level to minimize the number of alerts and surveys per physician and maximize the number of physicians eligible for survey participation.

\section{Intervention Details}

We developed a physician notification alert and survey and utilized REDCap (Research Electronic Data Capture) to email the alerts to each provider and to collect survey responses. ${ }^{25}$ The alert displayed individualized patient clinical information, including $\mathrm{CHA}_{2} \mathrm{DS}_{2}$-VASc stroke risk score and bleeding risk factors. In addition, we embedded a link to curated educational content and primary care guidelines relating to anticoagulation management developed and reviewed by a group of $\mathrm{MGH}$ physicians and specialists that is available as standard of care (eFigure 1). The survey asked the physician to confirm the AF diagnosis and anticoagulation status, provide input on who makes the anticoagulation decision, document reasons for not prescribing oral anticoagulants, and indicate what the next step in the management of this patient will be after receiving the alert (eFigure 2). The survey component of the physician alert was developed with input from a focus group of representative physicians within MGH. As an incentive, all physicians who completed surveys were provided with a $\$ 10$ café gift card and eligible to win one of three $\$ 250$ cash prizes. Physicians received email notifications on February 7, 2017, and up to three subsequent reminders over the 3-month follow-up period.

\section{Outcome Measures}

Patient characteristics, comorbidities, and prescriptions were obtained from a central data repository at Partners HealthCare. ${ }^{26}$ We calculated the ATRIA bleeding risk score for each patient by assigning three points for a diagnosis of anemia, three for renal disease, two for age $\geq 75$ years, one for prior hemorrhage, and one for hypertension. ${ }^{27}$ Physician characteristics were obtained from the hospital registrar.

The primary outcome was the proportion of patients prescribed oral anticoagulants at 3 months in the notification arm compared to the usual care arm. Secondary outcomes were survey-based reasons for not prescribing oral anticoagulants and planned next steps by physicians in response to the alert. Survey responses for reasons for not prescribing oral anticoagulants were pre-defined, with a free-text option. Two investigators independently reviewed all free-text responses provided by physicians for this question. Each investigator reclassified free-text responses into existing categories if possible, created new categories based on common free-text responses, and met to review any discordances in reclassification. Two investigators independently performed manual chart reviews of patients where a physician indicated the patient did not have $\mathrm{AF}$ to assess for any history of AF. A third investigator reviewed patient charts if there was discordance.

\section{Statistical Analyses}

Analyses were performed using SAS version 9.4 (SAS Institute, Cary, NC). For the primary outcome, we compared oral anticoagulant status at 3 months between the two arms using a logistic regression model accounting for clustering by physician using a generalized estimating equations approach (PROC GENMOD) in intention-to-treat analyses. We assessed the intervention effect in different subgroups based on whether patients had an office visit during the study period, patient age ( $\geq 75$ years and $<75$ years), gender, stroke risk $\left(\mathrm{CHA}_{2} \mathrm{DS}_{2}\right.$-VASc scores 2 or 3 and $\left.\geq 4\right)$, bleeding risk (ATRIA scores $0-3$ and $\geq 4$ ), and whether patients had prior history of oral anticoagulant use in the EMR. In separate models, we included an interaction term of treatment group (notification arm or usual care arm) with each subgroup to assess whether the effect of the alert was modified by visits, patient age, gender, stroke risk, bleeding risk, and prior oral anticoagulant use. Descriptive statistics to summarize survey data used mean or median for continuous variables and frequency with percentage for categorical variables. For the primary outcome, we considered a clinically meaningful difference in proportion of individuals adopting anticoagulation to be $4 \%$. Assuming up to $6 \%$ of patients in the usual care group were newly anticoagulated, the sample provided over 90\% power to detect this difference. The Partners Institutional Review Board approved this study with a waiver of written informed consent. The study was registered with ClinicalsTrials.gov (identifier NCT02950285). 
Data Availability. The datasets generated and/or analyzed during the current study are not publicly available due to protocol protections to minimize loss of patient confidentiality.

\section{RESULTS}

Among 175 participating physicians, the mean age was 50.4 years, $58.3 \%$ were female, with a mean of 22.6 years since medical school graduation and 15.7 years practicing at MGH. Among 6412 patients in the network with electronically ascertained $\mathrm{AF}$ and $\mathrm{CHA}_{2} \mathrm{DS}_{2}$-VASc score $\geq 2,57 \%$ were receiving anticoagulation as of the study start date. At baseline, demographics and clinical characteristics were similar between 972 patients randomized to the physician notification arm and 1364 patients in the usual care arm. The mean patient age was 76.0 years, $51.9 \%$ were female, and the mean $\mathrm{CHA}_{2} \mathrm{DS}_{2}$-VASc score was 4.2. Seventy-five percent of patients were being treated with antiplatelet therapy, most of whom $(69 \%)$ received aspirin alone (Table 1$)$. The proportion of patients who died or left the primary care network before the end of the 3-month study period was similar in both the notification $(n=60,6.2 \%)$ and usual care $(n=79,5.8 \%)$ arms.

\section{Proportion of Patients Prescribed Oral Anticoagulants}

Over the 3-month study period, the percentage of patients newly prescribed anticoagulants during follow-up was very small and not significantly different between the notification $(3.9 \%, 95 \%$ CI $2.8-5.3 \%, n=38)$ and usual care $(3.2 \%, 95 \%$ CI 2.4-4.2\%, $n=44)$ arms ( $p=0.37)$ (Fig. 3). The effect of the intervention was not statistically significant in any subgroup,

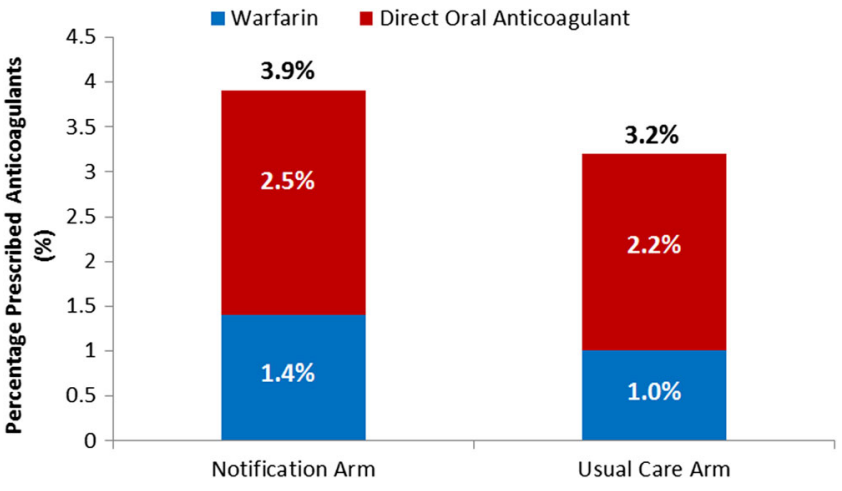

Figure 3 Percentage of patients prescribed oral anticoagulants at 3 months in intervention and usual care groups.

although the intervention effect was larger in magnitude among those with visits during the study period compared to those with no visit and among those with prior anticoagulation compared to those without prior anticoagulation. There was no difference in the (null) effect of the intervention by $\mathrm{CHA}_{2} \mathrm{DS}_{2}$ VASc or ATRIA bleeding risk score (interaction $p=0.51$ and 0.57 , respectively) (Fig. 4).

\section{Physician Survey Responses and Reasons for Not Prescribing Oral Anticoagulants}

Among 175 physicians, 101 (57.7\%) completed at least one survey corresponding to 454 of $972(46.7 \%)$ intervention patients. Physicians indicated that $422(93.0 \%)$ of 454 patients were properly attributed to them, $22(4.8 \%)$ were properly attributed but deceased, and $10(2.2 \%)$ were not their patient.

Physicians confirmed the diagnosis of AF in 180 (42.8\%) of 421 properly attributed patients $(n=1$ missing), indicated that $139(33.0 \%)$ had transient (resolved) or treated AF in the past, did not know the AF status for $3(0.7 \%)$, and did not think that $99(23.5 \%)$ had AF. Based on manual chart review, a diagnosis

Table 1 Baseline Patient Characteristics in Physician Notification and Usual Care Arms

\begin{tabular}{|c|c|c|c|}
\hline & All patients $(n=2336)$ & Physician notification $(n=972)$ & Usual care $(n=1364)$ \\
\hline Age, mean (SD) & $76.0(11.3)$ & $75.7(11.1)$ & $76.3(11.5)$ \\
\hline Gender, female & $1121(48.0 \%)$ & $482(49.6 \%)$ & $639(46.9 \%)$ \\
\hline Language, English & $2081(89.1 \%)$ & $869(89.4 \%)$ & $1212(88.9 \%)$ \\
\hline Race, white & $1985(85.0 \%)$ & $819(84.3 \%)$ & $1166(85.5 \%)$ \\
\hline Heart failure & $590(25.3 \%)$ & $254(26.1 \%)$ & $336(24.6 \%)$ \\
\hline Hypertension & $1867(79.9 \%)$ & $783(80.6 \%)$ & $1084(79.5 \%)$ \\
\hline Diabetes mellitus & $568(24.3 \%)$ & $231(23.8 \%)$ & $337(24.7 \%)$ \\
\hline Vascular disease & $816(34.9 \%)$ & $335(34.5 \%)$ & $481(35.3 \%)$ \\
\hline Prior stroke or transient ischemic attack & $717(30.7 \%)$ & $307(31.6 \%)$ & $410(30.1 \%)$ \\
\hline $\mathrm{CHA}_{2} \mathrm{DS}_{2}$-VASc, mean (SD) & $4.2(1.6)$ & $4.2(1.7)$ & $4.2(1.6)$ \\
\hline ATRIA bleeding risk score, mean (SD) & $3.9(2.4)$ & $4.0(2.5)$ & $3.9(2.3)$ \\
\hline History of anemia & $787(33.7 \%)$ & $337(34.7 \%)$ & $450(33.0 \%)$ \\
\hline Renal disease & $209(9.0 \%)$ & $99(10.2 \%)$ & $110(8.1 \%)$ \\
\hline Liver disease & $536(23.0 \%)$ & $234(24.1 \%)$ & $302(22.1 \%)$ \\
\hline Dementia & $231(9.9 \%)$ & $94(9.7 \%)$ & $137(10.0 \%)$ \\
\hline No prior oral anticoagulation use & $1220(52.2 \%)$ & $501(51.5 \%)$ & $719(52.7 \%)$ \\
\hline \multicolumn{4}{|l|}{ Current antiplatelet therapy } \\
\hline Aspirin & $1603(68.6 \%)$ & $671(69.0 \%)$ & $932(68.3 \%)$ \\
\hline Thienopyridine & $23(1.0 \%)$ & $7(0.7 \%)$ & $16(1.2 \%)$ \\
\hline Dual antiplatelet therapy & $129(5.5 \%)$ & $55(5.7 \%)$ & $74(5.4 \%)$ \\
\hline No antiplatelet therapy & $581(24.9 \%)$ & $239(24.6 \%)$ & $342(25.1 \%)$ \\
\hline
\end{tabular}




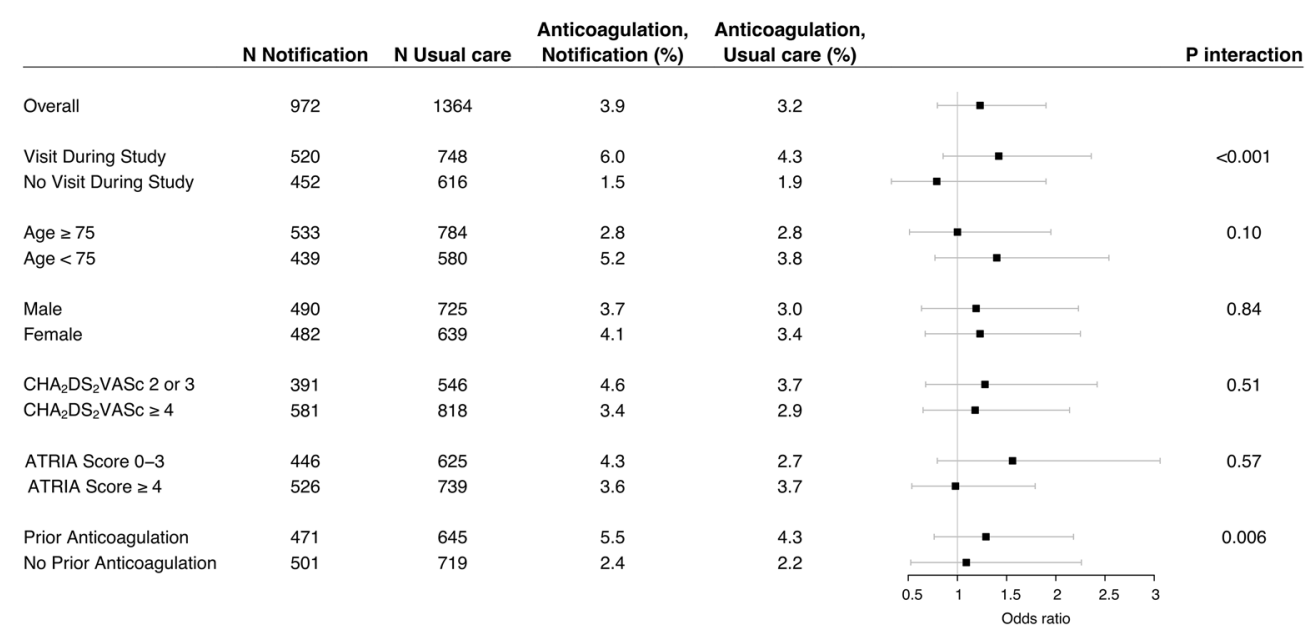

Figure 4 Odds ratios for the primary outcome (prescription of oral anticoagulants during follow-up) among subgroups of patient visits during the study period, patient age, gender, stroke risk, bleeding risk, and prior anticoagulation history.

of AF existed for $51 \%$ (50/99) of patients who the physician indicated did not have $\mathrm{AF}$ (most recent evidence documented in the medical record a median of 392.5 days [q1, 198 days; q3, 857.25 days] before study start date). Therefore, $11.6 \%$ of patients electronically ascertained as having AF did not have clinically evident AF.

Of the 319 patients that physicians characterized as having $\mathrm{AF}$ ( $n=180)$ or transient/treated $\mathrm{AF}$ in the past $(n=139)$, physicians reported that $89.0 \%(284 / 319)$ were properly classified as not currently taking an anticoagulant. Physicians stated they made the anticoagulation decision for approximately one-third of patients, cardiologists for one-third, and both the physician and cardiologist for one-third (eFigure 3). After omitting individuals with transient precipitants or resolved $\mathrm{AF}$, the proportion of patients in the intervention arm who were prescribed anticoagulation at 3 months was $8.3 \%$.

Among patients confirmed by their physician to not be taking an anticoagulant $(n=284)$, physicians documented reasons why (Table 2) and selected an average of 1.8 reasons per patient (median 1.0; eFigure 4). The most commonly selected reasons for a patient not receiving oral anticoagulants were that the patient (1) had transient AF in the setting of a reversible cause (30\%), (2) declined anticoagulation (22\%), (3) had a high risk of bleeding (20\%), (4) had a high risk of falls (19\%), (5) had other health issues (18\%), (6) had paroxysmal AF $(12 \%)$, and (7) was too frail (10\%). For $94.8 \%(253 / 267, n=$ 17 missing) of patients, physicians indicated that nothing would change in their management in response to the notification. After the study period, 44 of 175 (25.1\%) participating physicians opted-in to receive a list of their control patients.

\section{DISCUSSION}

In our study of primary care patients with $\mathrm{AF}$ at elevated stroke risk who were not prescribed oral anticoagulants, electronic notifications sent to primary care physicians did not increase guideline-based prescription of oral anticoagulants at 3 months following the notification. In surveys, most physicians indicated that the current management of patients was appropriate, and, in over $95 \%$ of patients, physicians stated

Table 2 Primary Care Physician Documented Reasons for a Patient Not Being on an Oral Anticoagulant

\begin{tabular}{|c|c|c|}
\hline Reason & $\begin{array}{l}\text { Frequency } \\
(n=284)\end{array}$ & Percent \\
\hline \multicolumn{3}{|l|}{ Stroke risk related } \\
\hline $\begin{array}{l}\text { Patient had transient AF in the setting } \\
\text { of a reversible cause and risk of } \\
\text { embolism is lower than suggested }\end{array}$ & 84 & $29.6 \%$ \\
\hline $\begin{array}{l}\text { Patient has paroxysmal AF and the } \\
\text { risk of embolism is lower than } \\
\text { suggested }\end{array}$ & 35 & $12.3 \%$ \\
\hline Patient has had an ablation & 19 & $6.7 \%$ \\
\hline $\begin{array}{l}\text { Patient's embolic risk is lower than } \\
\text { the } \mathrm{CHA}_{2} \mathrm{DS}_{2} \text {-VASc score suggests }\end{array}$ & 17 & $6.0 \%$ \\
\hline $\begin{array}{l}\text { Alternative to oral anticoagulation } \\
\text { chosen (e.g., left atrial appendage } \\
\text { exclusion procedure) }\end{array}$ & 2 & $0.7 \%$ \\
\hline \multicolumn{3}{|l|}{ Bleeding risk related } \\
\hline Patient's bleeding risk is too high & 56 & $19.7 \%$ \\
\hline Patient is at high risk of falls & 55 & $19.4 \%$ \\
\hline Patient is too frail & 29 & $10.2 \%$ \\
\hline $\begin{array}{l}\text { Patient had a bleed on anticoagulants } \\
\text { in the past }\end{array}$ & 23 & $8.1 \%$ \\
\hline \multicolumn{3}{|l|}{ Other patient-related factors } \\
\hline Patient (or their family) has declined & 61 & $21.5 \%$ \\
\hline $\begin{array}{l}\text { Patient has too many comorbidities/ } \\
\text { this is not the most important of their } \\
\text { problems }\end{array}$ & 51 & $18.0 \%$ \\
\hline Patient is unlikely to be compliant & 21 & $7.4 \%$ \\
\hline $\begin{array}{l}\text { Patient has poor mental status/ } \\
\text { dementia }\end{array}$ & 21 & $7.4 \%$ \\
\hline $\begin{array}{l}\text { Patient's quality of life would be } \\
\text { impaired if they took an } \\
\text { anticoagulant }\end{array}$ & 8 & $2.8 \%$ \\
\hline Patient is too old & 5 & $1.8 \%$ \\
\hline $\begin{array}{l}\text { Patient had poor INR control in the } \\
\text { past }\end{array}$ & 3 & $1.1 \%$ \\
\hline \multicolumn{3}{|l|}{ Physician or system-related factors } \\
\hline $\begin{array}{l}\text { Primary care physician defers to } \\
\text { cardiology }\end{array}$ & 22 & $7.8 \%$ \\
\hline $\begin{array}{l}\text { Limited infrastructure to support } \\
\text { education and management of } \\
\text { anticoagulant }\end{array}$ & 2 & $0.7 \%$ \\
\hline $\begin{array}{l}\text { Costs of anticoagulation are } \\
\text { prohibitive }\end{array}$ & 1 & $0.4 \%$ \\
\hline $\begin{array}{l}\text { Physician not comfortable with novel } \\
\text { anticoagulants }\end{array}$ & 0 & $0.0 \%$ \\
\hline
\end{tabular}


they would not change their management. Reasons for not prescribing oral anticoagulants included concerns that bleeding risk was too high or stroke risk was too low.

Despite guideline recommendations and efforts to increase the use of oral anticoagulants for patients with $\mathrm{AF}$, the proportion not treated with oral anticoagulants has remained between 40 and $50 \%$ even among patients at high risk of stroke. ${ }^{4-9}$ Many patients with AF at high risk of stroke are treated with aspirin alone, without oral anticoagulation. ${ }^{28} \mathrm{~A}$ multifaceted and multilevel educational intervention directed at both physicians and patients, with regular monitoring and feedback, was associated with a $9.1 \%$ absolute difference in change over 1 year compared to usual care in a prior study. ${ }^{29}$ Systematic reviews of studies involving physician alerts to improve delivery of preventive services have demonstrated modest impacts. ${ }^{30,} 31$ There has been limited research on electronic alerts targeting physicians for their AF patients not on oral anticoagulants. A prior randomized trial of an electronic alert for improving oral anticoagulant use among hospitalized oral anticoagulant-naïve AF patients demonstrated modest improvements in the proportion receiving anticoagulation at hospital discharge. ${ }^{17}$ A nonrandomized cohort study of a clinical alert for newly diagnosed hospitalized AF patients did not result in an increase in oral anticoagulant prescribing. ${ }^{15}$

In contrast, our study evaluated the impact of implementing an electronic alert for ambulatory primary care patients in a pragmatic randomized fashion. This trial was conducted outside of the context of a face-to-face clinic visit and represents an intervention that targets all AF patients at elevated stroke risk who are not anticoagulated. Our study was also distinctive in that we collected physician survey-based responses indicating why a patient was not on an oral anticoagulant.

Although the results of the intervention were null, we submit that our findings have three major clinical implications. First, physician notifications that include stroke and bleeding risk information are unlikely to decrease the $40-50 \%$ gap in oral anticoagulant use among patients with $\mathrm{AF}$ at increased risk of stroke. In this large randomized trial, few patients were newly prescribed oral anticoagulants over 3 months, with no difference between intervention and control groups. Though the notification included educational content and patientspecific information, physicians who completed a survey indicated they were aware of the patient's AF, stroke risk, and oral anticoagulant status and overwhelmingly reported that the alert would not change anticoagulation management.

Second, physicians believe their decisions not to use oral anticoagulants are appropriate. In this study, regardless of information provided in the electronic alert, physicians cited lower stroke and higher bleeding risk as chief concerns. Concerns about stroke and bleeding risk highlight the complexity of oral anticoagulant management in routine clinical practice. In the survey component of the current study, physicians documented an average of nearly two reasons for why a patient was not currently using an oral anticoagulant. The difficulty of increasing oral anticoagulant use may reflect the challenge physicians face when considering the potential harms and benefits of treating older patients with multiple comorbidities and bleeding risk factors.

Third, algorithm-based automated AF ascertainment schemes using EMR data may identify patients in whom the benefits and risks of anticoagulation for thromboembolism prophylaxis are controversial. For example, physicians identified patients with transient AF in the setting of a reversible cause as the most commonly selected reason for a patient not being on an anticoagulant in this study. Recent data has suggested that there may be increased risk of recurrent $\mathrm{AF}$ associated with prior episodes attributed to a secondary or reversible event, and substantial long-term risk of AF-related strokes may exist in such patients. ${ }^{32,}{ }^{33}$ Even after excluding patients with transient $\mathrm{AF}$ in the current study, only $8.3 \%$ of patients in the intervention arm were started on anticoagulants.

Prior consensus guidelines have suggested that AF may resolve with treatment of the reversible precipitant and therefore obviate the need for long-term anticoagulation, ${ }^{34}$ though more recent guidelines have highlighted a lack of randomized data to guide such decisions. ${ }^{35}$ Similarly, data increasingly suggest that the burden (amount of time spent in $\mathrm{AF}$ ) of $\mathrm{AF}$ may be associated with stroke risk, ${ }^{36,37}$ a factor which is not currently implemented in clinical guidelines and which electronic AF ascertainment algorithms do not generally take into account. The results of this study highlight the heterogeneity of what clinicians consider actionable AF for which long-term oral anticoagulation is indicated. Future studies should evaluate longitudinal outcomes among patients with reversible AF precipitants and assess whether oral anticoagulation is appropriate among these patients.

Our study should be interpreted in the context of the study design. Since it was conducted within a single primary care network, our findings may not be generalizable to other centers or care providers such as cardiologists. Randomization was at the patient level, so it is possible that the care of control patients may have been impacted by the intervention. We submit this is unlikely to have influenced the results given the infrequent use of anticoagulation in both arms. The electronic alert was conducted outside of a clinical encounter, which may have created an added burden for physicians to contact patients and modify treatment. Future point-of-care alerts may have a different impact on outcomes. It is possible that physicians may have ignored the email alert, whereas mandatory alerts with a hard-stop requirement may have yielded different results. Our AF algorithm misclassified approximately $12 \%$ of patients as having AF. Without misclassification, the percentage of patients anticoagulated after 3 months would be expected to be higher in both the intervention and control arms. While our alert included 
educational materials for providers, a more multifaceted approach that includes both provider and patient education, as well as regular monitoring and feedback, may be impactful. ${ }^{29}$ Only $58 \%$ of physicians completed a survey, however, this level of response is typical among physicians and we did not observe a significant difference in anticoagulation rates associated with survey response $(p=0.28) .{ }^{38,39}$ The survey element was directed to providers only and not to patients. There appears to be wide variability in patient and physician values related to risks and benefits of oral anticoagulation, and these values and preferences may often be discordant. ${ }^{40,41}$ Future efforts should explore the value of engaging the patients in AF anticoagulation interventions.

In conclusion, a very small percentage of patients were newly prescribed anticoagulants during the 3-month study period and electronic physician notifications did not increase anticoagulant prescriptions compared to usual care. Most physicians were aware of the patient's oral anticoagulation status and did not prescribe oral anticoagulants because they perceived bleed risk was too high or stroke risk was too low, the latter predominantly due to a history of transient AF. Despite the notifications, most physicians felt their decisions not to use oral anticoagulants were appropriate. In the current environment, where there is much clinical and public attention to anticoagulation for AF, electronic alerts and physician education are unlikely to substantially increase oral anticoagulant utilization in patients with AF.

Corresponding Author: Steven A. Lubitz, MD, MPH; Cardiovascular Research Center and Cardiac Arrhythmia Service Massachusetts General Hospital, Boston, MA, USA (e-mail: slubitz@mgh.harvard. edu).

\section{Contributors None}

Funders Dr. Lubitz is supported by NIH grants K23HL114724 and a Doris Duke Charitable Foundation Clinical Scientist Development Award 2014105. This work was supported by Grant 2016077 from the Doris Duke Charitable Foundation (Hulme/Lubitz). The study was sponsored by Boehringer Ingelheim, Inc (BIPI). BIPI had no role in the design, analysis, interpretation, or preparation of this manuscript. BIPI was given the opportunity to review the manuscript for medical and scientific accuracy as it relates to BIPI substances, as well as intellectual property considerations.

\section{Compliance with Ethical Standards:}

Prior Presentations: Dr. Ashburner presented this study as a finalist during the Samuel A. Levine Young Clinical Investigator Award Competition at the American Heart Association Scientific Sessions on November 11, 2017.

Conflict of Interest: Dr. Lubitz is supported by NIH grants K23HL114724 and a Doris Duke Charitable Foundation Clinical Scientist Development Award 2014105. Dr. Hulme and Lubitz were supported by Grant 2016077 from the Doris Duke Charitable Foundation. Dr. Ashburner has received grant funding from Boehringer Ingelheim and Bristol-Myers Squibb. Dr. Ellinor is the principal investigator on a grant from Bayer to the Broad Institute related to mechanism and therapeutics of atrial fibrillation. Dr. Lubitz receives sponsored research support from Bayer HealthCare, Biotronik, Bristol-Myers Squibb, and Boehringer Ingelheim and has consulted for St. Jude
Medical and Quest Diagnostics. Dr. Singer serves as a consultant or on the advisory board for Boehringer Ingelheim, Bristol-Myers Squibb, Merck, Johnson and Johnson, Medtronic, and Pfizer; he has funding from research grants from Boehringer Ingelheim, Bristol-Myers Squibb, and Med tronic related to preventing stroke in atrial fibrillation. Dr. Atlas has received grant funding from Boehringer Ingelheim and BristolMyers Squibb.

\section{REFERENCES}

1. Go AS, Hylek EM, Phillips KA, et al. Prevalence of diagnosed atrial fibrillation in adults: national implications for rhythm management and stroke prevention: the AnTicoagulation and Risk Factors in Atrial Fibrillation (ATRIA) Study. JAMA. 2001;285(18):2370-2375.

2. Wolf PA, Abbott RD, Kannel WB. Atrial fibrillation as an independent risk factor for stroke: the Framingham Study. Stroke. 1991;22(8):983988.

3. Risk factors for stroke and efficacy of antithrombotic therapy in atrial fibrillation. Analysis of pooled data from five randomized controlled trials. Arch Intern Med. 1994; 154(13): 1449-1457.

4. Gage BF, Boechler M, Doggette AL, et al. Adverse outcomes and predictors of underuse of antithrombotic therapy in medicare beneficiaries with chronic atrial fibrillation. Stroke. 2000;31(4):822-827.

5. Gladstone DJ, Bui E, Fang J, et al. Potentially preventable strokes in high-risk patients with atrial fibrillation who are not adequately anticoagulated. Stroke. 2009;40(1):235-240.

6. Glazer NL, Dublin S, Smith NL, et al. Newly detected atrial fibrillation and compliance with antithrombotic guidelines. Arch Intern Med. 2007;167(3):246-252.

7. Go AS, Hylek EM, Borowsky LH, Phillips KA, Selby JV, Singer DE. Warfarin use among ambulatory patients with nonvalvular atrial fibrillation: the anticoagulation and risk factors in atrial fibrillation (ATRIA) study. Ann Intern Med. 1999;131(12):927-934.

8. Hsu JC, Chan PS, Tang F, Maddox TM, Marcus GM. Differences in anticoagulant therapy prescription in patients with paroxysmal versus persistent atrial fibrillation. Am J Med. 2015;128(6):654 e651-654 e610.

9. Hsu JC, Maddox TM, Kennedy KF, et al. Oral anticoagulant therapy prescription in patients with atrial fibrillation across the spectrum of stroke risk: insights from the NCDR PINNACLE Registry. JAMA Cardiology. 2016;1(1):55-62.

10. Kakkar AK, Mueller I, Bassand JP, et al. Risk profiles and antithrombotic treatment of patients newly diagnosed with atrial fibrillation at risk of stroke: perspectives from the international, observational, prospective GARFIELD registry. PloS One. 2013;8(5):e63479.

11. Reynolds MR, Shah J, Essebag V, et al. Patterns and predictors of warfarin use in patients with new-onset atrial fibrillation from the FRACTAL Registry. Am J Cardiol. 2006;97(4):538-543.

12. Hsu JC, Freeman JV. Underuse of vitamin K antagonist and direct oral anticoagulants for stroke prevention in patients with atrial fibrillation: a contemporary review. Clinical Pharmacology and Therapeutics. 2018.

13. Ogilvie IM, Newton N, Welner SA, Cowell W, Lip GY. Underuse of oral anticoagulants in atrial fibrillation: a systematic review. Am J Med. 2010;123(7):638-645 e634.

14. Piazza G, Karipineni N, Goldberg HS, Jenkins KL, Goldhaber SZ. Underutilization of anticoagulation for stroke prevention in atrial fibrillation. J Am Coll Cardiol. 2016;67(20):2444-2446.

15. Cook DA, Enders F, Caraballo PJ, Nishimura RA, Lloyd FJ. An automated clinical alert system for newly-diagnosed atrial fibrillation. PloS One. 2015;10(4):e0122153.

16. Eckman MH, Lip GY, Wise RE, et al. Impact of an atrial fibrillation decision support tool on thromboprophylaxis for atrial fibrillation. Am Heart J. 2016;176:17-27.

17. Silbernagel G, Spirk D, Hager A, Baumgartner I, Kucher N. Electronic alert system for improving stroke prevention among hospitalized oralanticoagulation-naive patients with atrial fibrillation: a randomized trial. Journal of the American Heart Association. 2016;5(7).

18. Atlas SJ, Chang Y, Lasko TA, Chueh HC, Grant RW, Barry MJ. Is this "my" patient? Development and validation of a predictive model to link patients to primary care providers. J Gen Intern Med. 2006;21(9):973978.

19. Atlas SJ, Grant RW, Ferris TG, Chang Y, Barry MJ. Patient-physician connectedness and quality of primary care. Ann Intern Med. 2009; 150(5):325-335.

20. TopCare. SRG Technology website. srgtech.com/topcare. Published 2014. Accessed May 29, 2018. 
21. Khurshid S, Keaney J, Ellinor PT, Lubitz SA. A simple and portable algorithm for identifying atrial fibrillation in the electronic medical record. Am J Cardiol. 2016;117(2):221-225.

22. Lip GY, Nieuwlaat R, Pisters R, Lane DA, Crijns HJ. Refining clinical risk stratification for predicting stroke and thromboembolism in atrial fibrillation using a novel risk factor-based approach: the euro heart survey on atrial fibrillation. Chest. 2010;137(2):263-272.

23. Ashburner JM, Singer DE, Lubitz SA, Borowsky LH, Atlas SJ. Changes in use of anticoagulation in patients with atrial fibrillation within a primary care network associated with the introduction of direct oral anticoagulants. Am J Cardiol. 2017;120(5):786-791.

24. Linzer M, Bitton A, Tu SP, et al. The end of the 15-20 minute primary care visit. J Gen Intern Med. 2015;30(11):1584-1586.

25. Harris PA, Taylor R, Thielke R, Payne J, Gonzalez N, Conde JG. Research electronic data capture (REDCap)—a metadata-driven methodology and workflow process for providing translational research informatics support. Journal of Biomedical Informatics. 2009;42(2):377-381.

26. Murphy SN, Morgan MM, Barnett Go, Chueh HC. Optimizing healthcare research data warehouse design through past COSTAR query analysis. Proceedings / AMIA ... Annual Symposium. AMIA Symposium. 1999:892-896.

27. Fang MC, Go AS, Chang $\mathbf{Y}$, et al. A new risk scheme to predict warfarinassociated hemorrhage: The ATRIA (Anticoagulation and Risk Factors in Atrial Fibrillation) Study. J Am Coll Cardiol. 2011;58(4):395-401.

28. Hsu JC, Maddox TM, Kennedy $\mathbf{K}$, et al. Aspirin instead of oral anticoagulant prescription in atrial fibrillation patients at risk for stroke. J Am Coll Cardiol. 2016;67(25):2913-2923.

29. Vinereanu D, Lopes RD, Bahit MC, et al. A multifaceted intervention to improve treatment with oral anticoagulants in atrial fibrillation (IMPACTAF): an international, cluster-randomised trial. Lancet. 2017.

30. Baron RC, Melillo S, Rimer BK, et al. Intervention to increase recommendation and delivery of screening for breast, cervical, and colorectal cancers by healthcare providers a systematic review of provider reminders. American Journal of Preventive Medicine. 2010;38(1): 110-117.

31. Dexheimer JW, Talbot TR, Sanders DL, Rosenbloom ST, Aronsky D. Prompting clinicians about preventive care measures: a systematic review of randomized controlled trials. Journal of the American Medical Informatics Association : JAMIA. 2008;15(3):311-320.

32. Borowsky LH, Regan S, Chang Y, Ayres A, Greenberg SM, Singer DE. First diagnosis of atrial fibrillation at the time of stroke. Cerebrovasc Dis. 2017;43(3-4):192-199.
33. Lubitz SA, Yin X, Rienstra M, et al. Long-term outcomes of secondary atrial fibrillation in the community: the Framingham Heart Study. Circulation. 2015;131(19): 1648-1655.

34. Fuster V, Ryden LE, Cannom DS, et al. ACCF/AHA/HRS focused updates incorporated into the ACC/AHA/ESC 2006 guidelines for the management of patients with atrial fibrillation: a report of the American College of Cardiology Foundation/American Heart Association Task Force on practice guidelines. Circulation. 2011;123(10):e269-367.

35. January CT, Wann LS, Alpert JS, et al. AHA/ACC/HRS guideline for the management of patients with atrial fibrillation: a report of the American College of Cardiology/American Heart Association Task Force on Practice Guidelines and the Heart Rhythm Society. J Am Coll Cardiol. 2014;64(21):e1-76.

36. Boriani G, Glotzer TV, Santini M, et al. Device-detected atrial fibrillation and risk for stroke: an analysis of $>10,000$ patients from the SOS AF project (Stroke preventiOn Strategies based on Atrial Fibrillation information from implanted devices). European Heart Journal. 2014;35(8):508-516.

37. Turakhia MP, Ziegler PD, Schmitt SK, et al. Atrial fibrillation burden and short-term risk of stroke: case-crossover analysis of continuously recorded heart rhythm from cardiac electronic implanted devices. Circulation. Arrhythmia and electrophysiology 2015;8(5):1040-1047.

38. Cook JV, Dickinson HO, Eccles MP. Response rates in postal surveys of healthcare professionals between 1996 and 2005: an observational study. BMC Health Services Research. 2009;9:160.

39. Cunningham CT, Quan H, Hemmelgarn B, et al. Exploring physician specialist response rates to web-based surveys. BMC Medical Research Methodology. 2015; 15:32.

40. Alonso-Coello P, Montori VM, Diaz MG, et al. Values and preferences for oral antithrombotic therapy in patients with atrial fibrillation: physician and patient perspectives. Health Expectations : an international journal of public participation in health care and health policy. 2015;18(6):2318-2327.

41. MacLean S, Mulla S, Akl EA, et al. Patient values and preferences in decision making for antithrombotic therapy: a systematic review: antithrombotic therapy and prevention of thrombosis, 9th ed: American College of Chest Physicians Evidence-Based Clinical Practice Guidelines. Chest. 2012;141(2 Suppl):e1S-e23S. 